\title{
Monomethylmercury degradation by the human gut microbiota is stimulated by protein amendments
}

\author{
Galen Guo, Emmanuel Yumvihoze, Alexandre J. Poulain and Hing Man Chan \\ Department of Biology, Faculty of Science, University of Ottawa, Ottawa, Canada K1N 9B4
}

[Recommended by Akira Naganuma]

(Received September 8, 2018; Accepted September 10, 2018)

\begin{abstract}
Monomethylmercury (MMHg) is a potent neurotoxicant that can be bioaccumulated and biomagnified through trophic levels. Human populations whose diets contain MMHg are at risk of MMHg toxicity. The gut microbiota was identified as a potential factor causing variation in MMHg absorption and body burden. However, little is known about the role of gut microbiota on $\mathrm{Hg}$ transformations. We conducted a series of in vitro experiments to study the effects of dietary nutrient change on Hg metabolism and the human gut microbiota using anoxic fecal slurry incubations. We used stable Hg isotope tracers to track MMHg production and degradation and characterized the microbiota using high throughput sequencing of the 16S rRNA gene. We show that the magnitude of MMHg degradation is individual dependent and rapidly responds to changes in nutrient amendments, leading to complete degradation of the MMHg present. Although the mechanism involved remains unknown, it does not appear to involve the well-known mer operon. Our data are the first to show a nutrient dependency on the ability of the simulated human gut microbiota to demethylate MMHg. This work provides much-needed insights into individual variations in $\mathrm{Hg}$ absorption and potential toxicity.
\end{abstract}

Key words: Gut microbiome, Monomethylmercury, Metabolism, Mercury, Diet, Protein

\section{INTRODUCTION}

Global mercury $(\mathrm{Hg})$ pollution leads to an increase in monomethylmercury (MMHg) levels in fish and seafood and poses a health risk to human consumers (Mergler et al., 2007). The World Health Organization and the Food and Agriculture Organization recommend the consumption of fish as its health benefits outweigh the potential risk associated with MMHg toxicity (Food and Agriculture Organization of the United Nations and World Health Organization, 2011; Starling et al., 2015). To set these guidelines, the body burden of MMHg is often estimated by measuring $\mathrm{Hg}$ concentration in hair. However, there is considerable variation between the estimated MMHg oral intake and hair $\mathrm{Hg}$ concentrations in most populations tested (Canuel et al., 2006). To estimate human exposure to $\mathrm{MMHg}$, risk assessors often use standard models that assume that 90 to $100 \%$ of $\mathrm{MMHg}$ (Aberg et al., 1969) and 7-15\% of Hg (Miettinen, 1973) ingested is bioavailable. However, experimental evidence suggests that absorption estimates range from $12 \%$ to $79 \%$ for $\mathrm{MMHg}$ and $49 \%$ to $69 \%$ for inorganic divalent
(HgII) (Bradley et al., 2017). This discrepancy points to the existence of unidentified factors that are currently not considered in modelling the oral intake and body burden of MMHg.

The mechanism of absorption of MMHg from the intestine has been well documented (Naganuma et al., 1991). MMHg has a much higher absorption rate than $\mathrm{Hg}^{\mathrm{II}}$ (Bridges and Zalups, 2010). Therefore, the demethylation of MMHg in the gastrointestinal tract will decrease its absorption. The origin of the food, cooking methods and co-ingested micronutrients (e.g., selenium, fruit fibres) can potentially alleviate MMHg toxicity by reducing its bioavailability and bioaccessibility (Passos et al., 2007; Ralston and Raymond, 2010; Ouédraogo and Amyot, 2011). Li et al. (2016) have shown that age, body weight, gender, ethnicity, household income, and geographic regions only account for $32 \%$ of the total variance measured in hair $\mathrm{Hg}$ concentrations. The authors suggested that other factors such as diet or the activity of the gut microbiota might explain the remaining variance. Rand et al. (2016) reported a high degree of inter-individual variability in the MMHg biotransforma-

Correspondence: Hing Man Chan (E-mail: laurie.chan@uOttawa.ca) 
tion kinetics during a feeding experiment and proposed that the gut microbiome can be a significant modulating factor for MMHg absorption. Later, Caito et al. (2018) showed that individuals who received antibiotic therapy had lower MMHg elimination rates than untreated individuals, highlighting the importance of gut microbiota in the elimination of MMHg.

$\mathrm{Hg}$ biotransformation in the gut environment is largely unexplored. Few studies have reported that the gut of fish and zooplankton can potentially methylate $\mathrm{Hg}$ (Wang et al., 2013; Gorokhova et al., 2018) and the gut of rat and marine fish can demethylate MMHg (Nakamura et al., 1977; Rowland et al., 1984; Urano et al., 1990; Wang et al., 2017). The human gut does not appear to be a hotspot for MMHg production (Podar et al., 2015) but appears suitable for MMHg degradation (Rowland, 1988). Genes involved in $\mathrm{Hg}$ methylation $(h g c A$ and $h g c B)$ were not detected in the gut microbiome of healthy human individuals (Gilmour et al., 2013; Podar et al., 2015). However, genes involved in MMHg demethylation, encoded by the mer operon were detected (Osborn et al., 1997; Rothenberg et al., 2016).

There is a knowledge gap on the genetic determinants and microbial mechanisms involved in the biotransformation of $\mathrm{Hg}$ in the gut environment. Although a great emphasis has been placed on the mechanisms that control the formation of MMHg in sediments and soils, fewer studies have addressed the fate of MMHg after it is produced. Most of our knowledge of MMHg biotransformation was gathered from experiments performed outside the human gut (e.g., lake sediments, wetlands). Two pathways can usually be identified for bacterially mediated MMHg demethylation: (1) a reductive process, producing $\mathrm{Hg}^{0}$ and $\mathrm{CH}_{4}$ usually found in $\mathrm{Hg}$-contaminated sites (Barkay et al., 2003), and (2) an oxidative process producing $\mathrm{Hg}^{\mathrm{II}}$ and $\mathrm{CO}_{2}$ (Oremland et al., 1991; Martín-Díaz et al., 2008; Kronberg et al., 2018). The reductive process is mediated through an enzyme encoded by the mer-operon (organomercurial-lyase pathway) allowing microorganisms to be Hg-resistant. Oxidative demethylation possibly occurs via co-metabolism of MMHg and small organic compounds (Oremland et al., 1991), but the mechanism remains unknown. Recently, lab experiments using pure cultures have identified MMHg degradation by (micro)aerobic methanotrophs (e.g., $\mathrm{CH}_{4}$-consuming microbes) (Lu et al., 2017).

Because diet can affect the ecology of the gut microbiota (Singh et al., 2017), it is possible that nutrient intake from different diets can control the rate of MMHg degradation by affecting the gut microbiota community structure. Using an in vitro model, we manipulated the nutri- ent composition of fecal slurries prepared from two healthy human individuals and tracked MMHg production and degradation using stable $\mathrm{Hg}$ isotopes. Changes in microbial community structure were assessed using high throughput sequencing of 16S rRNA gene amplicon. Our hypothesis is that changes in the structure and function of the gut microbiota community induced by changes in dietary nutrient intake can affect the demethylation rate of MMHg.

\section{MATERIALS AND METHODS}

\section{Ethics}

Ethics application (H09-17-12) was reviewed and approved by the Research Ethics Board at the University of Ottawa. No information from participants was collected for this study.

\section{Fecal collection and incubation setup}

Fresh fecal samples $(<1$-hr old) collected from two healthy human volunteers were used as a proxy for distal gut microbiota. The volunteers had no history of gastrointestinal disorders, have consumed no antibiotics in the past six months, or any probiotics in the form of pills or food products in the last month. Feces were collected from two individuals in plastic commode provided. All manipulations were conducted under a nitrogen atmosphere devoided of oxygen in a Bactron anaerobic chamber (ShelLab). The fecal slurry was prepared by diluting 1-part fecal sample, 9-part degassed PBS prepared at pH 7.0. Fecal slurries were mechanically shaken and mixed in $100 \mathrm{~mL}$ glass bottle, in a 1:10 ratio with the respective medium: balanced (basal medium) (Olano-Martin et al., 2000), protein-rich (basal medium $+20 \mathrm{~g} \cdot \mathrm{L}^{-1}$ peptone) and carbohydrate-rich (basal medium $+10 \mathrm{~g} . \mathrm{L}^{-1}$ glucose). Bottles were spiked with stable isotope enriched $\mathrm{MM}^{198} \mathrm{Hg}$ and ${ }^{199} \mathrm{Hg}$ isotopes are added to the mix to measure $\mathrm{Hg}$ methylation and demethylation using LC-ICP-MS. This ratio was chosen to reflect that of MMHg:Hg in the gut environment. Final concentrations were $[\mathrm{MMHg}]=10 \mathrm{ng} \cdot \mathrm{g}^{-1}$ and $\left[\mathrm{Hg}^{\mathrm{II}}\right]=1 \mathrm{ng} \cdot \mathrm{g}^{-1}$, and were lower than levels typically found in fish meal. All treatments were performed in biological triplicates. Serum bottles containing the samples were crimped to ensure anaerobic conditions and wrapped in aluminum foil to limit light exposure. Bottles were placed in a shaking incubator at $37^{\circ} \mathrm{C}$. Bottles were sampled at $\mathrm{t}=0,12,24,36$ and $48 \mathrm{hr}$ for $\mathrm{Hg}$ transformation analysis and $\mathrm{t}=0$ and $48 \mathrm{hr}$ for microbial analysis. Samples were stored in $15 \mathrm{~mL}$ falcon tubes kept at $-20^{\circ} \mathrm{C}$ for microbial community analysis and in small $7 \mathrm{~mL}$ scintillation vial kept at $-80^{\circ} \mathrm{C}$ for $\mathrm{Hg}$ isotope anal- 
ysis.

\section{Probiotic and transfer experiment}

Sutterella parvirubra (DSMZ-19354) and Acidaminococcus intestini (DSMZ-21505) were commercially obtained from the DSMZ to test for their demethylation potential. Both strains were grown as per DSMZ cultivation conditions. Strains were tested for their methylation and demethylation potential in the balanced medium. In another series of experiments, Sutterella parvirubra or Acidaminococcus intestini were added to individual B fecal slurry to test for their potential to induce a demethylation phenotype. Finally, to test the effect of transferring the gut microbiota of individual $\mathrm{A}$ into individual $\mathrm{B}$, fecal slurry preparation of individuals $\mathrm{A}$ and $\mathrm{B}$ was added in 1:1 (5 mL of individual $\mathrm{A}$ and $5 \mathrm{~mL}$ of individual $\mathrm{B})$ and $1: 2(3.3 \mathrm{~mL}$ of individual $\mathrm{A}$ and $6.7 \mathrm{~mL}$ of individual B) ratio.

\section{Hg analyses}

Samples were prepared according to the modified protocol outlined by Batista et al. (2011). All analysis and mercury isotope separation were performed on an Agilent LC-ICP-MS system. Chromatographic separation of isotope $\mathrm{MM}^{198} \mathrm{Hg}$ (demethylation tracer), ${ }^{199} \mathrm{Hg}$ (methylation tracer), ${ }^{201} \mathrm{Hg}$ (internal standard), and ${ }^{202} \mathrm{Hg}$ (ambient) was performed using a mobile phase consisting of $0.05 \% \mathrm{v} / \mathrm{v}$ mercaptoethanol, $0.4 \% \mathrm{~m} / \mathrm{v}$ L-cysteine and $0.06 \mathrm{M}$ ammonium acetate on Agilent 1200 Infinity LC system consisting of a 1260 Isocratic pump and 1260 Autosampler. The LC system was connected to the Agilent 7700x ICP-MS via Peek tubing and equipped with a low flow Micro Mist Nebulizer and quartz, low-volume Scott-type double-pass spray chamber. All calculations for quantifying excess of $\mathrm{MM}^{199} \mathrm{Hg}$ and $\mathrm{MM}^{198} \mathrm{Hg}$ were made according to Hintelmann and Evans (1997). Additional information can be found in supporting methods.

\section{Microbial community analysis using 16S rRNA gene amplicon metagenomic}

DNA was extracted using the PowerSoil ${ }^{\circledR}$ DNA Isolation Kit (Mo Bio Laboratories, Carlsbad, CA, USA). Sequencing was performed by Molecular Research LP (Shallowater, TX, USA), which amplified DNA using a two-step PCR targeting the V4 hypervariable region of the 16S rRNA gene using the primer $515 \mathrm{f}$ (forward: GTGYCAGCMGCCGCGGTAA) and 806r (reverse: GGACTACNVGGGTWTCTAAT). A negative control of our DNA extraction kit was performed using PBS 1X as a sample. We were not able to obtain an amplicon and no band was observed on a gel electrophoresis; samples were sent to the sequencing facility which was also unable to reliably generate amplicons for sequencing.

Amplicon sequence datasets were analyzed using the Quantitative Insights into Microbial Ecology (QIIME) pipeline (Caporaso et al., 2010a). The data was quality filtered using QIIME default parameters (quality score $=25$, min length $=200$, max length $=1000$ ). Additional quality filtering and operational taxonomic unit (OTU) clustering were performed the UCHIME algorithm to identify chimera sequences for removal against the Gold databases. Remaining sequences were clustered into OTU (97\% identity) using Closed reference OTU picking with UCLUST to form the representative dataset. Taxonomical classification of the representative dataset was performed using Ribosomal Database Project's classifier against the SILVA database as a reference using the default settings (DeSantis et al., 2006). The representative sequences for each OTU were aligned using PyNAST (Caporaso et al., 2010b).

\section{Statistical analysis}

All analyses were performed in R v. 3.3.2 (R Core Team 2017). Beta diversity, weighted Unifrac distances, were used to perform the principal coordinate analyses (PCoA) using the package Vegan (http://www.cran.rproject.org/package $=$ vegan). Data separation in the PCoA was tested using a permutational multivariate analysis of variance (PERMANOVA; function Adonis in the Vegan package). Hierarchical cluster analysis was performed using weight Unifrac distance dissimilarity matrix Two-way analyses of variance (ANOVA) with Tukey multiple comparisons were used to evaluate differences in $\mathrm{Hg}$ methylation and demethylation potential between medium and incubation time.

\section{RESULTS AND DISCUSSION}

Using fecal slurry incubations, we conducted a series of experiments aiming to evaluate the potential for the gut microbiota to affect $\mathrm{Hg}$ speciation under different nutritional profiles for two healthy human adult individuals, referred to as individuals A and B. At $48 \mathrm{hr}$ postincubation, $\mathrm{MM}^{198} \mathrm{Hg}$ levels in individual A fecal slurries incubated in protein-rich medium were undetectable (Fig. 1A, Fig. S1; $<<0.001$ ). In the balanced diet treatment, $\mathrm{MM}^{198} \mathrm{Hg}$ concentrations decreased by $52.5 \%$. No significant decrease was observed in the carbohydraterich treatment (Fig. 1A). Strikingly, MMHg degradation was muted in individual B samples (Fig. 1B; Fig. S1). We did not observe significant production of $\mathrm{MM}^{199} \mathrm{Hg}$ in any of the treatments, supporting previous reports that 

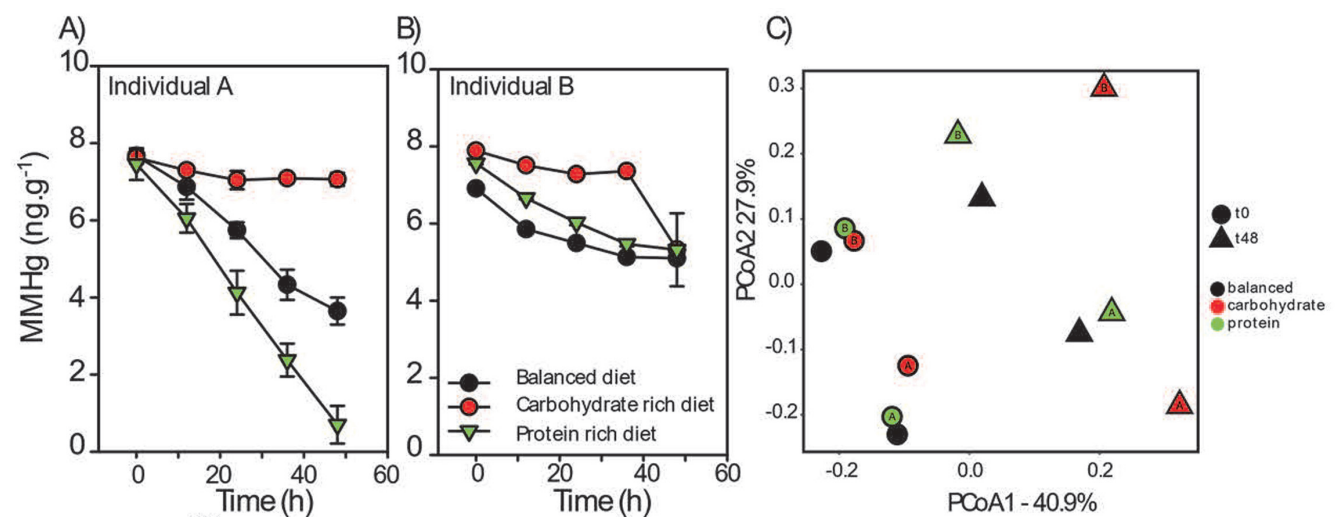

Fig. 1. $\mathrm{MM}^{198} \mathrm{Hg}$ concentrations over time for individuals $\mathrm{A}(\mathrm{A})$ and $\mathrm{B}(\mathrm{B})$. Fecal slurries from individual $\mathrm{A}$ and $\mathrm{B}$ were prepared in balanced medium, balanced medium enriched with carbohydrates or balanced medium enriched with proteins. (C) A principal coordinates analysis based on characterization of the overall fecal community structure for individuals A and B. Weighted UniFrac metrics was calculated using QIIME to compute microbial $\beta$ diversity. Sample dissimilarities were projected on a two-dimensional axis using principal coordinate analysis (PCoA). * indicates any significant difference between treatment and control.

the gut microbiota is not a hotspot for MMHg formation (Fig. S2). Control abiotic experiments (balanced, carbohydrate- and protein-rich treatments amended with stable isotope) did not show changes in $\mathrm{Hg}$ isotope concentrations ( $\mathrm{MM}^{198} \mathrm{Hg}$ and ${ }^{199} \mathrm{Hg}$; Fig. S3). These results suggest that i) the ability to degrade MMHg is individual dependent and ii) that protein amendments stimulate pathways that lead to MMHg degradation. All experiments were conducted in darkness, ruling out the possibility of abiotic demethylation of MMHg via photodegradation (Seller et al., 1996).

Individuals $\mathrm{A}$ and $\mathrm{B}$ exhibited similar gut microbial community structures (Fig. 1C, Fig. 2), which were both dominated by Firmicutes and Bacteroidetes $(>80 \%$ in relative abundance), as expected from the gut microbiota of healthy human individuals (Ley et al., 2008). The addition of $\mathrm{Hg}$ did not significantly affect the microbial community structure suggesting that the $\mathrm{Hg}$ tracer added did not significantly alter the gut microbiota community structure (Fig. 2). Using PERMANOVA (Adonis), we are able to identify the incubation time ( $\mathrm{T} 0$ vs T48) as a variable that significantly affected the microbial community structure in both individuals (Fig. 1C; $p=0.002$ ). Carbohydraterich medium post-incubation also significantly shifted the microbial community structure that is different from the structure observed in the balanced and protein-rich medium (Fig. 1C; $p=0.007$ ). The carbohydrate-rich treatment promoted the growth of Actinobacteria whereas balanced and protein-rich media saw an increased abundance of phyla that were already dominating the gut microbial profile at $\mathrm{T} 0$. The carbohydrate-rich treatment also decreased baseline MMHg degradation rates observed in individual A (Fig. S1). One possible explanation for the absence of MMHg degradation in the carbohydrate treatment could be the production of compounds inhibiting MMHg degradation. Indeed, Lu et al. (2017) showed that C1 compounds could inhibit oxidative MMHg degradation. Further investigation is required to determine if the same process takes place in the human gut environment.

A more detailed analysis of the changes in the microbial community structure showed that individual A exhibited a significant increase in Sutterellaceae and Acidaminococcaceae $(0.44 \rightarrow 15.34 \%)$ in the protein-rich medium after $48 \mathrm{hr}$ of treatment (Table 1) that was not observed for individual B (Table 1). Both bacterial families are known to be commensal of the human gut (D'Auria et al., 2011; Morotomi et al., 2011).

In a subsequent series of experiments, commercially obtained Sutterella parvirubra (DSMZ-19354) and Acidaminococcus intestini (DSMZ-21505) were tested for their MMHg degradation capabilities in balanced and protein-rich media. A. intestini incubated in proteinrich medium exhibited significantly higher demethylation rates than in the balanced medium. S. parvirubra did not show a significant change in MMHg degradation rates compare to control (Fig. 3). When both strains were combined together (1:1 ratio), MMHg demethylation rate was significantly higher than control but much lower than what was observed in the fecal slurry experiments $\left(0.14 \mathrm{nM} \cdot \mathrm{g}^{-1} \cdot \mathrm{hr}^{-1}\right.$ of $\mathrm{MM}^{198} \mathrm{Hg}$, vs $6.7 \mathrm{nM} \cdot \mathrm{g}^{-1} \cdot \mathrm{hr}^{-1}$ of $\mathrm{MM}^{198} \mathrm{Hg}$, respectively; Fig. 3).

The next experiment was to add S. parvirubra and $A$. 


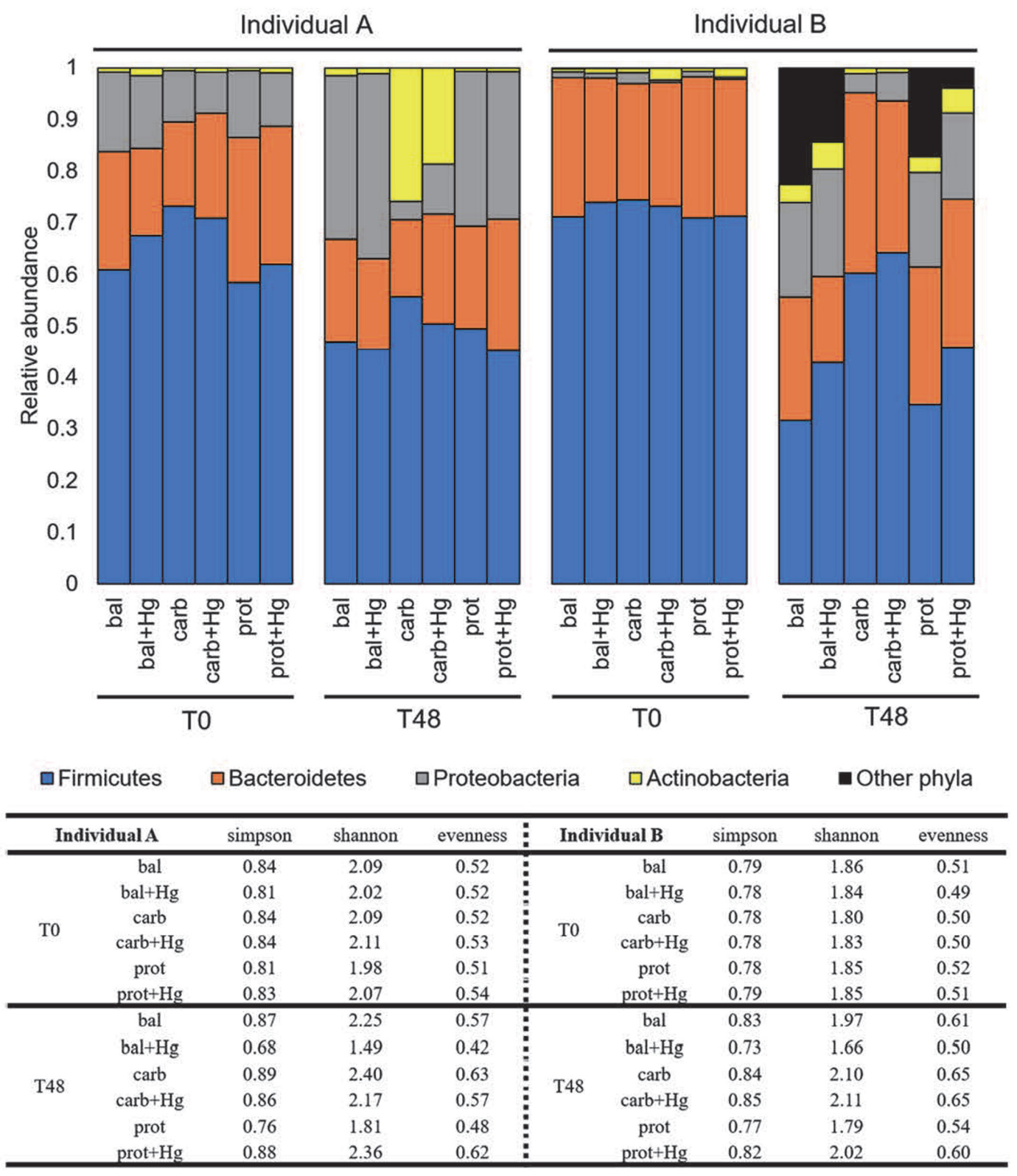

Fig. 2. (Top) Barplot showing relative abundance (phylum level) from the high-throughput $16 \mathrm{~S}$ rRNA amplicon sequencing of the control experiment testing for the effect of the $\mathrm{Hg}$ tracer added. The table displays alpha diversity calculated for both individuals at the family level. An ANOVA did not detect any significant differences.

intestini strains to fecal slurries collected from individual B to test whether they would enhance the demethylation of $\mathrm{MMHg}$. We did not observe significant changes in MMHg metabolism with the addition of $S$. parvirubra or A. intestini in individual B fecal slurries (Fig. 4). These data suggest that MMHg demethylation does not result from the isolated activity of these two sin- gle strains. These results indicate that the increased abundance of these two strains in the demethylating individual likely reflects more complex changes within the gut microbial community. The enhanced degradation of MMHg as a result of protein addition could be explained by syntrophic interactions, in which microorganisms are linked via metabolic handoffs (Abreu and Taga, 2016; 
Table 1. Table representing both taxa that increase in the MMHg degradation treatment and the relative proportion in other treatment.

\begin{tabular}{lccc}
\hline & & Balanced (\%) & Protein (\%) \\
\hline Individual A & Sutterellaceae & $0.08 \rightarrow 0.33$ & $0.22 \rightarrow 7.87^{*}$ \\
& Acidaminococcaceae & $0.05 \rightarrow 2.46^{*}$ & $0.23 \rightarrow 7.87^{*}$ \\
\hline Individual B & Sutterellaceae & $0.08 \rightarrow 0.04$ & $0.07 \rightarrow 0.04$ \\
& Acidaminococcaceae & $\mathrm{N} / \mathrm{A}$ & $\mathrm{N} / \mathrm{A}$ \\
\hline
\end{tabular}

All values are relative proportion in percentage. $(*)$ represent significant difference $(\mathrm{p}<0.001)$. Acidaminococcaceae was not detected in individual B.

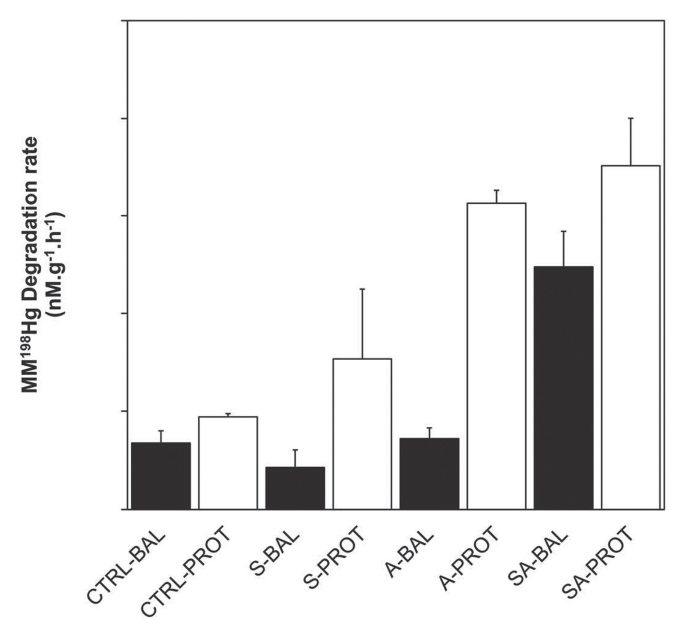

Fig. 3. Demethylation from pure culture Sutterella parivubra (S) and Acidaminococcus intestini (A) in balanced (BAL) and protein-rich (PROT) media. Control treatments consisted of media with no microbial amendments. Letters represent significant differences: (a) indicate significant differences between nutrient amendment added while (b) indicate significant differences between treatment and abiotic control (ANOVA and Tukey post-hoc; $\mathrm{p}<0.001)$.

Anantharaman et al., 2016). Syntrophic interactions have already been identified as important in the production of MMHg (Yu et al., 2018) and deserve further investigations to evaluate their role in MMHg degradation.

Finally, to test whether the absence of MMHg degradation in individual $\mathrm{B}$ was the result of a communitylevel inhibitory process, we performed a series of fecal mixing experiments. In these experiments, fecal samples from individual A (strong demethylator phenotype) and $\mathrm{B}$ (weak demethylator phenotype) were mixed in different ratio. We observed that degradation of $\mathrm{MMHg}$ was increasingly higher with increasing ratio of fecal samples from individual A (Fig. 5). These data suggest that the microbial community of individual B did not inhibit the degradation of $\mathrm{MMHg}$ and that individual A fecal

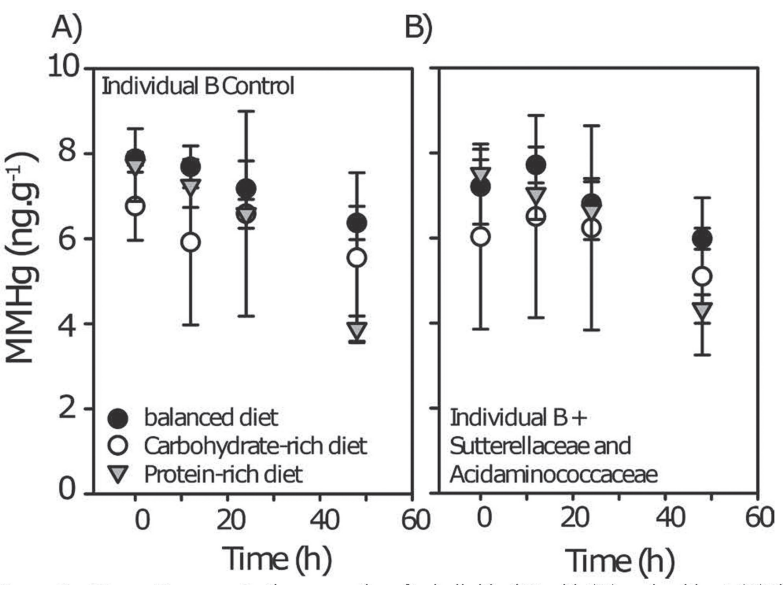

Fig. 4. $\mathrm{MM}^{198} \mathrm{Hg}$ concentrations over time for individual $\mathrm{B}$ with (A) and, without (B) the addition of S. parivubra and A. intestini.

samples consistently exhibit a microbial community that can be stimulated to enhance MMHg degradation in vitro. We tested for the presence of genes encoding for the mer operon to test if these genes were responsible for the higher demethylation capacity of the microbiota of individual A. None of the mer operon genes that we targeted were present in the gut microbiota of either individual A or B (data not shown).

We cannot yet offer a convincing mechanism explaining the quasi-complete demethylation phenotype observed for individual A in the presence of proteins. Nevertheless, these data are the first to show a nutrient dependency on the ability of the human gut microbiota to demethylate $\mathrm{MMHg}$ in vitro. We are currently gathering evidence testing how widespread this superdemethylation phenotype is at the human population level. This research contributes to the understanding of the roles that the gut microbiota and nutrient intake have on $\mathrm{Hg}$ metabolism. Should a reproducible mechanistic relationship between diet, microbiota community structure and function, and $\mathrm{MMHg}$ demethylation phenotype be identified, this research could lead to 


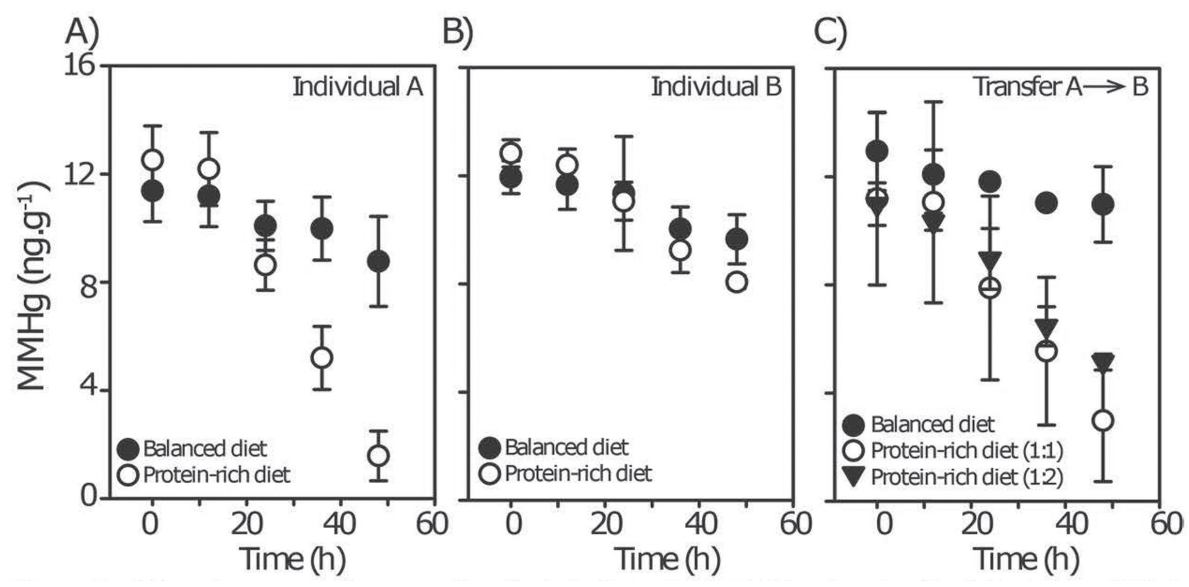

Fig. 5. $\mathrm{MM}^{198} \mathrm{Hg}$ concentrations over time for individuals $\mathrm{A}(\mathrm{A}), \mathrm{B}(\mathrm{B})$ and a mix of individual $\mathrm{A}$ and $\mathrm{B}$ (1:1 and 1:2, A:B, respectively) (C) prepared in balanced medium and balanced medium amended with protein. Note that $\mathrm{MM}{ }^{199} \mathrm{Hg}$ concentrations did not change across treatments suggesting the absence of methylation (Fig. S3). * indicates any significant difference between treatment and control.

a shift in how risk assessment is conducted.

\section{Supporting information}

Contains additional methodological details and additional results further supporting the main findings.

\section{ACKNOWLEDGMENTS}

Our work was funded by NSERC Discovery (AJP, HMC), Accelerator grant (AJP), CFI funding (AJP, HMC), Canada Research Chair (HMC) and an NSERC CREATE-REACT scholarship to GG. We are grateful to the participants of this study that have contributed fecal samples and for Poulain and Chan lab members for stimulating discussion. We would like to thank Morgan McMillan for her help with the analyses.

Conflict of interest---- The authors declare that there is no conflict of interest.

\section{REFERENCES}

Aberg, B., Ekman, L., Falk, R., Greitz, U., Persson, G. and Snihs, J.O. (1969): Metabolism of methyl mercury (203Hg) compounds in man. Arch. Environ. Health, 19, 478-484.

Abreu, N.A. and Taga, M.E. (2016): Decoding molecular interactions in microbial communities. FEMS Microbiol. Rev., 40, 648663.

Anantharaman, K., Brown, C.T., Hug, L.A., Sharon, I., Castelle, C.J., Probst, A.J., Thomas, B.C., Singh, A., Wilkins, M.J., Karaoz, U., Brodie, E.L., Williams, K.H., Hubbard, S.S. and
Banfield, J.F. (2016): Thousands of microbial genomes shed light on interconnected biogeochemical processes in an aquifer system. Nat. Commun., 7, 13219.

Barkay, T., Miller, S.M. and Summers, A.O. (2003): Bacterial mercury resistance from atoms to ecosystems. FEMS Microbiol. Rev., 27, 355-384.

Batista, B.L., Rodrigues, J.L., de Souza, S.S., Oliveira Souza, V.C. and Barbosa, F. Jr. (2011): Mercury speciation in seafood samples by LC-ICP-MS with a rapid ultrasound-assisted extraction procedure: application to the determination of mercury in Brazilian seafood samples. Food Chem., 126, 2000-2004.

Bradley, M.A., Barst, B.D. and Basu, N. (2017): A Review of Mercury Bioavailability in Humans and Fish. Int. J. Environ. Res. Public Health, 14, 169.

Bridges, C.C. and Zalups, R.K. (2010): Transport of inorganic mercury and methylmercury in target tissues and organs. J. Toxicol. Environ. Health B Crit. Rev., 13, 385-410.

Caito, S.W., Jackson, B.P., Punshon, T., Scrimale, T., Grier, A., Gill, S.R., Love, T.M., Watson, G.E., van Wijngaarden, E. and Rand, M.D. (2018): Editor's Highlight: Variation in Methylmercury Metabolism and Elimination Status in Humans Following Fish Consumption. Toxicol. Sci., 161, 443-453.

Canuel, R., de Grosbois, S.B., Atikessé, L., Lucotte, M., Arp, P., Ritchie, C., Mergler, D., Chan, H.M., Amyot, M. and Anderson, R. (2006): New evidence on variations of human body burden of methylmercury from fish consumption. Environ. Health Perspect., 114, 302-306.

Caporaso, J.G., Bittinger, K., Bushman, F.D., DeSantis, T.Z., Andersen, G.L. and Knight, R. (2010b): PyNAST: a flexible tool for aligning sequences to a template alignment. Bioinformatics, 26, 266-267.

Caporaso, J.G., Kuczynski, J., Stombaugh, J., Bittinger, K., Bushman, F.D., Costello, E.K., Fierer, N., Peña, A.G., Goodrich, J.K., Gordon, J.I., Huttley, G.A., Kelley, S.T., Knights, D., Koenig, J.E., Ley, R.E., Lozupone, C.A., McDonald, D., Muegge, B.D., Pirrung, M., Reeder, J., Sevinsky, J.R., 
Turnbaugh, P.J., Walters, W.A., Widmann, J., Yatsunenko, T., Zaneveld, J. and Knight, R. (2010a): QIIME allows analysis of high-throughput community sequencing data. Nat. Methods, 7 , 335-336.

D’Auria, G., Galán, J.-C., Rodríguez-Alcayna, M., Moya, A., Baquero, F. and Latorre, A. (2011): Complete genome sequence of Acidaminococcus intestini RYC-MR95, a Gram-negative bacterium from the phylum Firmicutes. J. Bacteriol., 193, 70087009.

DeSantis, T.Z., Hugenholtz, P., Larsen, N., Rojas, M., Brodie, E.L., Keller, K., Huber, T., Dalevi, D., Hu, P. and Andersen, G.L. (2006): Greengenes, a chimera-checked 16S rRNA gene database and workbench compatible with ARB. Appl. Environ. Microbiol., 72, 5069-5072.

Food and Agriculture Organization of the United Nations and World Health Organization. (2011): Report of the Joint FAO/WHO Expert Consultation on the Risks and Benefits of Fish Consumption : Rome, 25-29 January 2010. Food and Agriculture Organization of the United Nations.

Gilmour, C.C., Podar, M., Bullock, A.L., Graham, A.M., Brown, S.D., Somenahally, A.C., Johs, A., Hurt, R.A. Jr., Bailey, K.L. and Elias, D.A. (2013): Mercury methylation by novel microorganisms from new environments. Environ. Sci. Technol., 47, 11810-11820.

Gorokhova, E., Soerensen, A.L. and Motwani, N.H. (2018): Mercury-methylating bacteria are associated with zooplankton: a proof-of-principle survey in the Baltic Sea. bioRxiv, 279976.

Hintelmann, H. and Evans, R.D. (1997): Application of stable isotopes in environmental tracer studies - Measurement of monomethylmercury $(\mathrm{CH} 3 \mathrm{Hg}+$ ) by isotope dilution ICP-MS and detection of species transformation. Fresenius J. Anal. Chem., 358, 378-385.

Kronberg, R.-M., Schaefer, J.K., Björn, E. and Skyllberg, U. (2018): Mechanisms of Methyl Mercury Net Degradation in Alder Swamps: The Role of Methanogens and Abiotic Processes. Environ. Sci. Technol. Lett., 5, 220-225.

Ley, R.E., Hamady, M., Lozupone, C., Turnbaugh, P.J., Ramey, R.R., Bircher, J.S., Schlegel, M.L., Tucker, T.A., Schrenzel, M.D., Knight, R. and Gordon, J.I. (2008): Evolution of mammals and their gut microbes. Science, 320, 1647-1651.

Li, M., von Stackelberg, K., Rheinberger, C.M., Hammitt, J.K., Krabbenhoft, D.P., Yin, R. and Sunderland, E.M. (2016): Insights from mercury stable isotopes into factors affecting the internal body burden of methylmercury in frequent fish consumers. Elem. Sci. Anth., 4, 103.

Lu, X., Gu, W., Zhao, L., Farhan U1 Haque, M., DiSpirito, A.A., Semrau, J.D. and Gu, B. (2017): Methylmercury uptake and degradation by methanotrophs. Sci. Adv., 3, e1700041.

Martín-Díaz, M.L., Jiménez-Tenorio, N., Sales, D. and Delvalls, T.A. (2008): Accumulation and histopathological damage in the clam Ruditapes philippinarum and the crab Carcinus maenas to assess sediment toxicity in Spanish ports. Chemosphere, 71, 1916-1927.

Mergler, D., Anderson, H.A., Chan, L.H., Mahaffey, K.R., Murray, M., Sakamoto, M. and Stern, A.H.; Panel on Health Risks and Toxicological Effects of Methylmercury. (2007): Methylmercury exposure and health effects in humans: a worldwide concern. Ambio, 36, 3-11.

Miettinen, J.K. (1973): Absorption and elimination of dietary $(\mathrm{Hg}++)$ and methylmercury in man. In: Mercury, Mercurial, and Mercaptans (Miller, M.W. and Clarkson,T.W., eds.), pp.233-246, Springfield, IL.
Morotomi, M., Nagai, F. and Watanabe, Y. (2011): Parasutterella secunda sp. nov., isolated from human faeces and proposal of Sutterellaceae fam. nov. in the order Burkholderiales. Int. J. Syst. Evol. Microbiol., 61, 637-643.

Naganuma, A., Tanaka, T., Urano, T. and Imura, N. (1991): Role of Glutathione in Mercury Disposition. In: Advances in Mercury Toxicology, pp.111-120, Springer US, Boston, MA.

Nakamura, I., Hosokawa, K., Tamura, H. and Miura, T. (1977): Reduced mercury excretion with feces in germfree mice after oral administration of methyl mercury chloride. Bull. Environ. Contam. Toxicol., 17, 528-533.

Olano-Martin, E., Mountzouris, K.C., Gibson, G.R. and Rastall, R.A. (2000): In vitro fermentability of dextran, oligodextran and maltodextrin by human gut bacteria. Br. J. Nutr., 83, 247-255.

Oremland, R.S., Culbertson, C.W. and Winfrey, M.R. (1991): Methylmercury decomposition in sediments and bacterial cultures: involvement of methanogens and sulfate reducers in oxidative demethylation. Appl. Environ. Microbiol., 57, 130-137.

Osborn, A.M., Bruce, K.D., Strike, P. and Ritchie, D.A. (1997): Distribution, diversity and evolution of the bacterial mercury resistance (mer) operon. FEMS Microbiol. Rev., 19, 239-262.

Ouédraogo, O. and Amyot, M. (2011): Effects of various cooking methods and food components on bioaccessibility of mercury from fish. Environ. Res., 111, 1064-1069.

Passos, C.J., Mergler, D., Fillion, M., Lemire, M., Mertens, F., Guimarães, J.R. and Philibert, A. (2007): Epidemiologic confirmation that fruit consumption influences mercury exposure in riparian communities in the Brazilian Amazon. Environ. Res., 105, 183-193.

Podar, M., Gilmour, C.C., Brandt, C.C., Soren, A., Brown, S.D., Crable, B.R., Palumbo, A.V., Somenahally, A.C. and Elias, D.A. (2015): Global prevalence and distribution of genes and microorganisms involved in mercury methylation. Sci. Adv., 1, e1500675-e1500675.

Ralston, N.V. and Raymond, L.J. (2010): Dietary selenium's protective effects against methylmercury toxicity. Toxicology, 278, 112-123.

Rand, M.D., Vorojeikina, D., van Wijngaarden, E., Jackson, B.P., Scrimale, T., Zareba, G., Love, T.M., Myers, G.J. and Watson, G.E. (2016): Methods for Individualized Determination of Methylmercury Elimination Rate and De-Methylation Status in Humans Following Fish Consumption. Toxicol. Sci., 149, 385395.

Rothenberg, S.E., Keiser, S., Ajami, N.J., Wong, M.C., Gesell, J., Petrosino, J.F. and Johs, A. (2016): The role of gut microbiota in fetal methylmercury exposure: insights from a pilot study. Toxicol. Lett., 242, 60-67.

Rowland, I.R. (1988): Interactions of the gut microflora and the host in toxicology. Toxicol. Pathol., 16, 147-153.

Rowland, I.R., Robinson, R.D. and Doherty, R.A. (1984): Effects of diet on mercury metabolism and excretion in mice given methylmercury: role of gut flora. Arch. Environ. Health, 39, 401-408.

Seller, P., Kelly, C.A., Rudd, J.W. and MacHutchon, A.R. (1996): Photodegradation of methylmercury in lakes. Nature, 380, 694697.

Singh, R.K., Chang, H.-W., Yan, D., Lee, K.M., Ucmak, D., Wong, K., Abrouk, M., Farahnik, B., Nakamura, M., Zhu, T.H., Bhutani, T. and Liao, W. (2017): Influence of diet on the gut microbiome and implications for human health. J. Transl. Med., 15, 73.

Starling, P., Charlton, K., McMahon, A.T. and Lucas, C. (2015): Fish intake during pregnancy and foetal neurodevelopment--a systematic review of the evidence. Nutrients, 7, 2001-2014. 
Urano, T., Iwasaki, A., Himeno, S., Naganuma, A. and Imura, N. (1990): Absorption of methylmercury compounds from rat intestine. Toxicol. Lett., 50, 159-164.

Wang, H.-S., Xu, W.-F., Chen, Z.-J., Cheng, Z., Ge, L.-C., Man, Y.B., Giesy, J.P., Du, J., Wong, C.K. and Wong, M.H. (2013): In vitro estimation of exposure of Hong Kong residents to mercury and methylmercury via consumption of market fishes. J. Hazard.
Mater., 248-249, 387-393.

Wang, X., Wu, F. and Wang, W.-X. (2017): In Vivo Mercury Demethylation in a Marine Fish (Acanthopagrus schlegeli). Environ. Sci. Technol., 51, 6441-6451.

Yu, R.-Q., Reinfelder, J.R., Hines, M.E. and Barkay, T. (2018): Syntrophic pathways for microbial mercury methylation. ISME J., 12, 1826-1835. 